\title{
Identification and Quantification of Uncertainties in a Hydrodynamic River Model Using Expert Opinions
}

\author{
Jord J. Warmink • Hanneke Van der Klis • Martijn \\ J. Booij · Suzanne J. M. H. Hulscher
}

Received: 29 January 2010 / Accepted: 20 September 2010 /

Published online: 6 October 2010

(C) The Author(s) 2010. This article is published with open access at Springerlink.com

\begin{abstract}
Hydrodynamic river models are applied to design and evaluate measures for purposes such as safety against flooding. The modelling of river processes involves numerous uncertainties, resulting in uncertain model outcomes. Knowledge of the type and magnitude of uncertainties is crucial for a meaningful interpretation of the model results and the usefulness of results in decision making processes. The aim of this study is to identify the sources of uncertainty that contribute most to the uncertainties in the model outcomes and quantify their contribution to the uncertainty in the model outcomes. Experts have been selected based on an objective Pedigree analysis. The selected experts are asked to quantify the most important uncertainties for two situations: (1) the computation of design water levels and (2) the computation of the hydraulic effect of a change in the river bed. For the computation of the design water level, the uncertainties are dominated by the sources that do not change between the calibration and the prediction. The experts state that the upstream discharge and the empirical roughness equation for the main channel have the largest influence on the uncertainty in the modeled water levels. For effect studies, the floodplain bathymetry, weir formulation and discretization of floodplain topography contribute most to the uncertainties in model outcomes. Finally, the contribution of the uncertainties to the model outcomes show that the uncertainties have a significant effect on the predicted water levels, especially under design conditions.
\end{abstract}

Keywords Expert opinion - Uncertainty analysis • Pedigree analysis • River modelling $\cdot$ Hydraulic roughness $\cdot$ River Rhine

J. J. Warmink ( $\otimes)$ · M. J. Booij · S. J. M. H. Hulscher

Department of Water Engineering and Management, University of Twente,

Enschede, The Netherlands

e-mail: j.j.warmink@utwente.nl

H. Van der Klis

Deltares, Delft, The Netherlands 


\section{Introduction}

Hydraulic-morphological river models are applied to design and evaluate measures for purposes such as safety against flooding. These numerical models are all based on a deterministic approach. However, the modelling of river processes involves numerous uncertainties, resulting in uncertain model outcomes. Knowledge of the type and magnitude of uncertainties is crucial for a meaningful interpretation of the model results and the usefulness of results in decision making processes.

Uncertainty is defined by Walker et al. (2003) as "any deviation of the unachievable ideal of complete determinism". Uncertainty consists of inaccuracy and imprecision. Inaccuracy refers to the difference of a model outcome with reality, while imprecision deals with the variation around the model outcome and observations. Model uncertainty can be classified according to Walker et al. (2003) along three dimensions: the location, level and nature of an uncertainty.

The uncertainty in model outcomes can be quantified by propagation of the quantified uncertainty in all parts of the model. Monte Carlo simulation is a commonly used method for uncertainty propagation (Morgan and Henrion 1990), especially for highly non-linear models (Van der Klis 2003). Monte Carlo simulation requires a quantification of the uncertainties in all parts of the model as input. Therefore, to determine the total uncertainty in the model outcomes, a structural analysis and quantification of the sources of uncertainty in a model is required. Many uncertainty studies are based on strong assumptions of the variation of the underlying uncertainties. However, the reliability of the uncertainty analysis is very sensitive to the assumed coefficient of variation (Johnson 1996). The problem is that information about the magnitude and probability distribution functions of this input is usually not available or insufficient (Johnson 1996; Van der Sluijs 2007). Furthermore, the uncertainty in the underlying uncertainty strongly depends on the case study and the model under consideration (Warmink et al. 2010).

In recent uncertainty analysis studies about river modelling, uncertainties have often been studied in isolation. Often, only uncertainties that can easily be quantified are taken into account, such as uncertainties in model input and model parameters (e.g. Refsgaard et al. 2006a; Hall et al. 2005; Bates et al. 2004). In such a case, it is likely that the model outcome uncertainty is underestimated. The uncertainties in the model context and model structure are often neglected. Although, Refsgaard et al. (2006b) present a method to deal with uncertainties in model structure, the authors do not consider other sources of uncertainty.

Pappenberger et al. (2005) and Hunter et al. (2007) give a structured overview of uncertainties in river models. They review the recent developments in reduced complexity of river models to determine the extent to which such techniques are capable of reliable and practical application. However, they only focus on uncertainties in the input, parameters and model structure of river models. They do not include the uncertainties in the context and application of the model in the review. Hall and Solomatine (2008) and Van der Keur et al. (2008, 2010) describe and identify the individual sources of uncertainty in a broader context. They focus on uncertainties in water resources management, including flood risk management. However, they do not quantify the sources of uncertainty, nor do they quantify the uncertainty in the model outcomes. 
A substitute for the information about the magnitude and probability distribution functions of the input for an uncertainty analysis is the use of subjective probability functions, which can be obtained by the systematic combination of expert judgments (Van der Sluijs 1997; Cooke and Goossens 2000; Ayyub 2001). In environmental modelling, especially for health risk analysis, expert opinion has been used for the identification and quantification of uncertainties (Krayer von Krauss et al. 2004; Van der Sluijs et al. 2005a; Refsgaard et al. 2006b).

Krayer von Krauss et al. (2004) conducted detailed expert interviews to formally explore the uncertainty in the risk assessment on genetically modified crops. They interviewed seven leading experts in this research field to obtain qualitative and quantitative information from their understanding of the uncertainties associated with the risks. Van der Sluijs et al. (2005b) studied the emission of volatile organic compounds (VOC) from paint in The Netherlands. The authors used expert elicitation to identify key sources of error, critical assumptions and bias in the monitoring process. Both these studies by Krayer von Krauss et al. (2004) and Van der Sluijs et al. (2005b) comprise an uncertainty assessment, combining quantitative and qualitative data, in a risk assessment. In our study we assess the uncertainty in the outcomes of a hydrodynamic river model, thereby focusing on quantification of the uncertainties in the model outcomes.

In this study we want to identify and quantify the uncertainties in a two dimensional river model used for flood safety computations in a structured manner. Expert opinion elicitation has been used, to identify the most important uncertainties in the river model, which will be used in a future study as the first step in a Monte Carlo analysis. The reliability of the outcomes of a Monte Carlo analysis depend on the reliability of the identified sources of uncertainty. Therefore, the aim of this study is to identify the sources of uncertainty that contribute most to the uncertainties in the model outcomes and quantify their contribution to the uncertainty in the model outcomes using expert opinion elicitation.

This paper is organized as follows. Section 2 describes the case study used. The method for the selection of the experts and the approach for the interviews is presented in Section 3. In Section 4 the results are given and discussed in Section 5. Finally, conclusions are drawn in Section 6.

\section{Case Study}

River flooding is a serious threat in the Netherlands. Strong dikes have been constructed to protect the land from flooding. After the 1993 and 1995 near flood events of the rivers Rhine and Meuse, the Dutch government laid down that every 5 years the safety of the primary dikes has to be evaluated (Ministry of Transport, Public Works and Water Management 1995). The Ministry of Transport, Public Works and Water Management publishes every five year the Hydraulic Boundary conditions. These comprise the water levels that are used in the safety assessment. They are determined using statistical and deterministic models.

The design water levels in the main rivers in The Netherlands are computed based on a design discharge (Ministry of Transport, Public Works and Water Management 1995). This design discharge is based on the statistical analysis of historical discharge 
series. Subsequently, the heights of the dikes are compared to the computed design water levels in the river. These design water levels are the main components of the dike safety evaluation.

The design water levels in the upper part of the Dutch Rhine branches are calculated using the two-dimensional, depth-averaged river model WAQUA. The WAQUA model has been developed in the late sixties, based on the work of Leendertse (1967). WAQUA is used for two-dimensional hydrodynamic and water quality simulation of well-mixed estuaries, coastal seas and lowland rivers. The WAQUA model is used and maintained by the Road and Hydraulic Engineering Institute of the Directorate General of Public Works and Water Management in cooperation with Deltares (former WL | Delft Hydraulic). WAQUA accounts for flooding and drying of individual cells and can account for energy losses due to weirs. These features are essential for channelized rivers, such as the river Rhine. The model is applied mainly to the Dutch Rhine tributaries and for several studies of the river Rhine in Germany.

WAQUA consists of: 1) the program environment SIMONA (Rijkswaterstaat 2009) which holds the discretized shallow water equations to simulate the water flow and the empirical equations to approximate energy losses, and 2) a schematization of the upper river Rhine region for a certain period with corresponding input parameters (e.g. stage-discharge relations, river bed roughnesses, upstream discharge, etc.). The schematization consists of a computational grid, the bathymetry of the river bed and mapped characteristics of the flow channel (e.g. grain size, vegetation, and other objects such as houses, bridges, barriers, spillways, etc.). The vegetation is represented by a hydraulic roughness that is calibrated for different classes of vegetation types (Van Velzen et al. 2003). Aerial photography is used to determine the vegetation type for each polygon in the floodplain area. Subsequently, these data are converted onto the computational grid. In this study, the 2006 version of the WAQUA model (HR2006_4) was used, which has grid sizes of approximately $40 \mathrm{~m}$ (Rijkswaterstaat 2007). The time required to simulate one full day for the Dutch distributaries is approximately one hour using a time step of $15 \mathrm{~s}$.

The WAQUA model is used for two different applications. Firstly, for the computation of the design water levels (DWL) as described above. Secondly, the model is used for the computation of the effect of measures taken in the floodplain areas that change the geometry of the cross section, so called effect studies. This is the case if, for example, someone wants to exploit the floodplain for building or clay excavations. In this case the changes in the floodplain region are not allowed to result in a rise in the water level in the river. Therefore, the plans are tested using the WAQUA model by schematizing the plans in the model and computing the effect. Another example of effect studies is that the Ministry of Transport, Public Works and Water Management wants to lower the design water levels in the Dutch rivers by increasing the discharge capacity of the floodplains. Therefore, the effect of different measures on the design water levels are compared using the WAQUA model.

The main differences between DWL computations and effect studies are that the DWL case uses a design discharge wave as input, while the effect studies use a constant discharge as upstream input. Furthermore, the result from a DWL computation is an absolute water level in the river, while for the effect studies case, the result is a difference in water levels. This means that for effect studies, two 
model runs are subtracted, which has large implications for the uncertainties. For both applications the effect at the river axis (the center line of the main channel) and near the dike are computed.

Calibration of the WAQUA model has been carried out using the measured discharge peak of 1995, with corresponding schematization and measured water levels at several locations along the River Rhine (Van den Brink et al. 2006). The 1995 peak is used as it is the highest measured discharge peak in the River Rhine in recent history and is, therefore, closest to the design discharge of $16,000 \mathrm{~m}^{3} / \mathrm{s}$. The 1995 peak had a maximum discharge of $12,000 \mathrm{~m}^{3} / \mathrm{s}$ at Lobith (the location where the Rhine enters The Netherlands). During this calibration only one linear parameter in the equation that relates the hydraulic roughness of the main channel to the water level is adapted so that the computed water levels of the seven stations along the river Waal match the measured water levels. In the setup of the model, also optimal values for several other parameters, such as the eddy viscosity are determined.

The experts were asked to consider only the WAQUA model for the Waal branch for the two above mentioned applications. The Waal river is the largest branch of the river Rhine in the Netherlands. Figure 1 shows the location of the Waal branch in the Netherlands and the schematization of the WAQUA model. This model was well known to all interviewed experts.

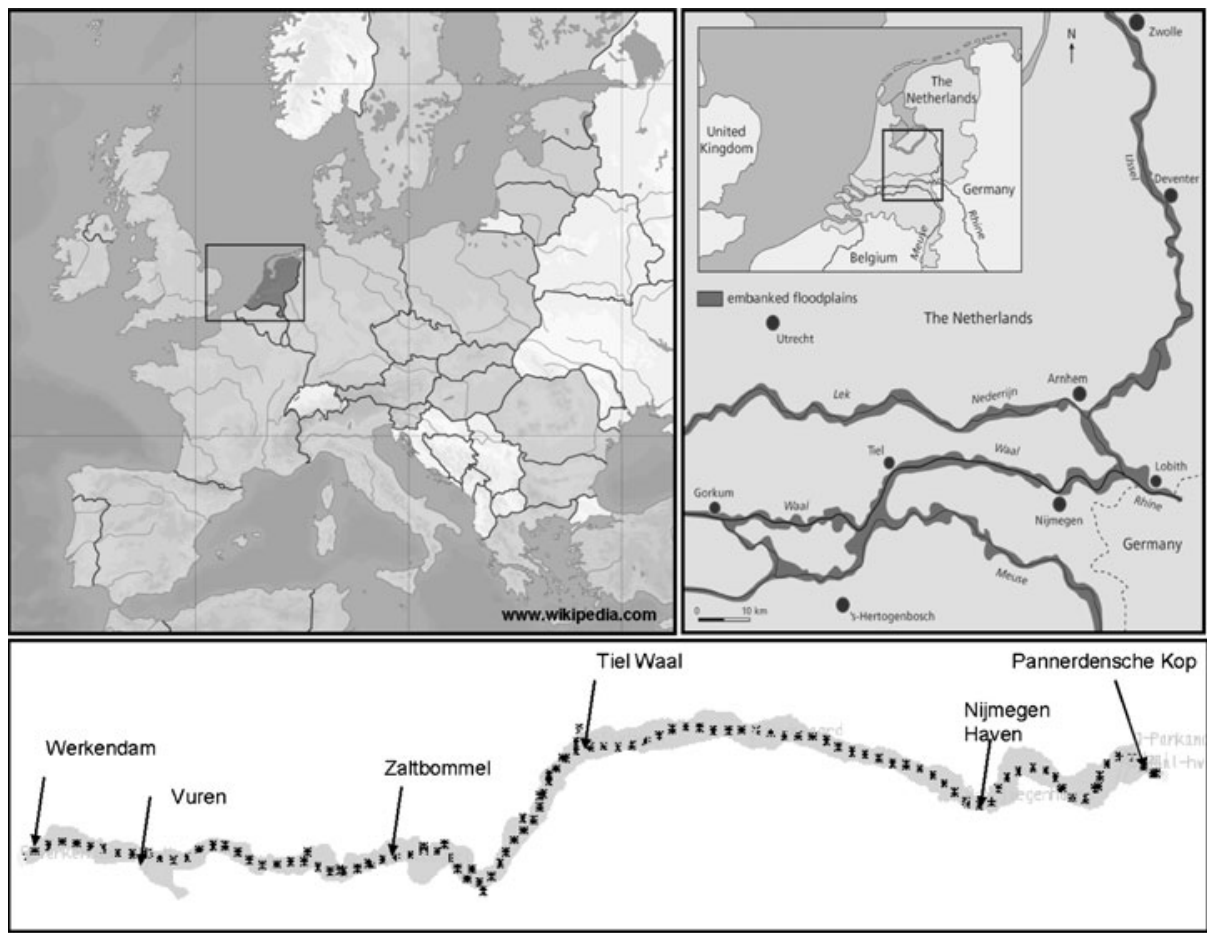

Fig. 1 Location of the Rhine distributaries in The Netherlands. The Waal model is shown below with the measurement stations indicated by the arrows and the river kilometers as black crosses 


\section{Method}

The first step in an expert opinion study is to select the experts. Van der Sluijs (1997) notes that the results of an expert opinion study are sensitive to the selection of the experts whose estimates are gathered. In this study, the experts have been selected based on their expertise that has been measured using a Pedigree analysis. Next, eleven face-to-face interviews have been conducted with the selected experts and the experts' opinions have been aggregated.

\subsection{Pedigree Analysis}

In this study the experts are selected using objective criteria in a Pedigree analysis. Pedigree is a method to convey an evaluative account of the production process of information and indicates different aspects of the underpinning of the numbers and scientific status of the knowledge used (Funtowicz and Ravetz 1990). Pedigree is expressed by means of a set of pedigree criteria to assess these different aspects (Van der Sluijs et al. 2005b).

Pedigree analysis is used in uncertainty analysis, commonly as part of the NUSAP methodology (Van der Sluijs et al. 2004). NUSAP is a notational system proposed by Funtowicz and Ravetz (1990), which aims to provide an analysis and diagnosis of uncertainty in science for policy. It captures both quantitative and qualitative dimensions of uncertainty and enables one to display these in a standardized way. The basis idea is to qualify quantities using the five qualifiers of the NUSAP acronym: Numerical, Unit, Spread, Assessment and Pedigree. By well describing and framing the uncertainties (Numerical and Unit) and adding expert judgment of reliability (Assessment) and systematic multi-criteria of the production process of numbers (Pedigree), NUSAP has extended the statistical approach (Spread) (Van der Sluijs et al. 2004). The Pedigree part of NUSAP is developed to describe and quantify the background of different types of information.

Pedigree is used to assess the 'strength' of an assumption, input or parameter. The strength means that the assumption underlying the quantity is 'weak' or 'strong'. Different criteria are defined on which this strength is evaluated. To minimize arbitrariness and subjectivity in measuring strength, a Pedigree matrix is used to code qualitative expert judgments for different criteria into a discrete numerical scale from 0 (weak) to 4 (strong) with linguistic descriptions (the criteria) of each level on the scale. Each special sort of information has its own aspects that are key to its Pedigree (Van der Sluijs et al. 2004). The criteria may vary, depending on the audience and case at hand. Common criteria include: quality of proxy, empirical basis, theoretical understanding, methodological rigor, validation, and value-ladenness (Wardekker et al. 2008). Assessment of Pedigree involves qualitative expert judgment and is therefore commonly used in combination with expert opinion elicitation.

Pedigree has been applied in several uncertainty analysis studies in combination with expert opinion elicitation. Groenenberg and Van der Sluijs (2005) used Pedigree analysis for determining the strength of uncertain assumptions, input and parameters in an emission reduction targets model as an addition to a sensitivity analysis. They concluded that in the identification of the major uncertainties in their model, one should not only consider the variance in the outcome, but also to pay attention to the strength of various inputs. This means that the values of the parameters with 
the lowest strength need to be chosen based on maximal research and consultation of stakeholders (Groenenberg and Van der Sluijs 2005), because a quantitative sensitivity analysis might show that these parameters only have little influence on the model outcomes. However, a low strength indicates that the background of these parameters is potentially highly uncertain. Therefore, they may have a large effect on the uncertainty in the model outcomes, which is not revealed by the quantitative analysis only.

Van der Sluijs (2002) showed the experiences in applying Pedigree, as an addition to quantitative methods in an uncertainty analysis to four cases: a policy case, a complex model case, a chain of models and an interactive assessment of uncertainty in environmental health risk science and policy. In both model cases they used expert opinions to assess Pedigree scores to determine the strength of the underlying assumptions and model input and parameters. They concluded that Pedigree is a useful addition to quantitative sensitivity analysis to prioritize uncertainties. Wardekker et al. (2008) analyzed a series of experiments evaluating uncertainty communication in the yearly reports that describe the state of the (Dutch) environment and evaluate policy influences. They show that policy advisors find qualitative information on uncertainty presented by Pedigree scores useful to put the presented data in perspective. In this study, we used Pedigree to determine the strength of the experts and assess their level of expertise.

\subsection{Application of Pedigree for Expert Selection}

The first reason to select an expert was its familiarity with the case study. Initially 42 possible experts have been selected who were familiar with the WAQUA model. All experts have been either involved in research activities related to the WAQUA model or in WAQUA project execution. Most experts had "hands-on" experience with the WAQUA model, that is they have been working on setting up and running the model personally.

From these 42 initially selected experts we needed to select between 10 and 15 experts for a face-to-face interview given the available time. Expert opinions are sensitive to the selection of experts (Van der Sluijs 1997), therefore, an objective method to select the experts was required. We used the Pedigree method to measure the expertise of the experts and selected the experts with the highest expertise. A Pedigree matrix has been developed for measuring the expertise for this particular case. We chose four different criteria that we considered most appropriate to determine the experts' expertise. Subsequently, for each criterion five possible answers have been prepared ranging from 0 (low expertise) to 4 (large expertise). A short questionnaire has been send to the experts to get the input for the Pedigree analysis.

The four criteria in the Pedigree matrix are: 1) number of years experience with research and consultancy projects regarding the WAQUA model, 2) the number of years experience with the WAQUA model applied to the rivers Rhine or Meuse, 3) experience with code development of the WAQUA model and 4) number and type of publications about research projects with the WAQUA model concerning the rivers Rhine or Meuse. The Pedigree matrix is shown in Table 1.

We gave the criteria within the Pedigree matrix a relative weight, because not all criteria are considered equally important. The criteria have been given a weight between 1 and 4 . We considered experience with code development the most 
Table 1 Pedigree matrix for the selection of experts, based on Funtowicz and Ravetz (1990)

\begin{tabular}{|c|c|c|c|c|}
\hline Question & Project experience & Model experience & Code development & Publications \\
\hline$\overline{\text { Weights }}$ & 3 & 2 & $\overline{4}$ & 1 \\
\hline 4 & Yes $\geq 10$ years & $\geq 10$, Rhine & Yes, $\geq 10$ years & Journal paper \\
\hline 3 & Yes $\leq 10$ years & $\geq 10$, No Rhine & Yes, long time ago & Conference \\
\hline 2 & Only related models & $\geq 5$, Rhine & Yes, some & Report \\
\hline 1 & Only 1D models & $\geq 5$, No Rhine & Few & Few \\
\hline 0 & No & $\overline{\mathrm{N}}_{\mathrm{O}}$ & No & No \\
\hline
\end{tabular}

important criterion, because it has been assumed that people that have information about the code background have more insight in the model and can therefore better judge the uncertainties in the model. The second most important criterion was experience with WAQUA projects for the same reason, followed by "handson" experience. Number of publications was considered to be the least important criterion. The Pedigree score for each expert was determined by:

$$
P=\frac{\sum_{i=1}^{4} \mathrm{col}_{i} \cdot w_{i}}{40}
$$

where $\operatorname{col}_{i}$ is the number of points in column $i$ and $w_{i}$ is the weight of that column. To normalize $P$ between 0 and 1 , we divide here by 40 , which is the maximum number of point that can be scored. A sensitivity analysis on the influence of the weights on the selected experts showed that only two experts would be excluded if the weights were omitted and all criteria would have the same weight. So, the weights do not have a large influence on the selection of the experts, but it improves the representation of the expertise of each expert by the Pedigree score.

Thirty-one experts returned the questionnaire and have been given a Pedigree score, based on their answers of the questionnaire. Figure 2 shows the results of the Pedigree analysis. The 17 experts with a Pedigree score above 0.65 were selected and invited for an interview. The threshold of 0.65 was chosen because the trend of the Pedigree scores shows a clear drop after expert 17 and time was available for 10 to 15 experts. Experts 25-30 did not complete the questionnaire, but answered that they were not the intended expert, therefore they were assigned a zero Pedigree score.

Subsequently, 11 of the 17 selected experts are actually interviewed. The interviewed experts all had a Pedigree score of 0.75 or higher, which indicates that all

Fig. 2 Pedigree scores of all experts that returned the questionnaire. Seventeen experts with a Pedigree score above 0.65 have been selected for an interview

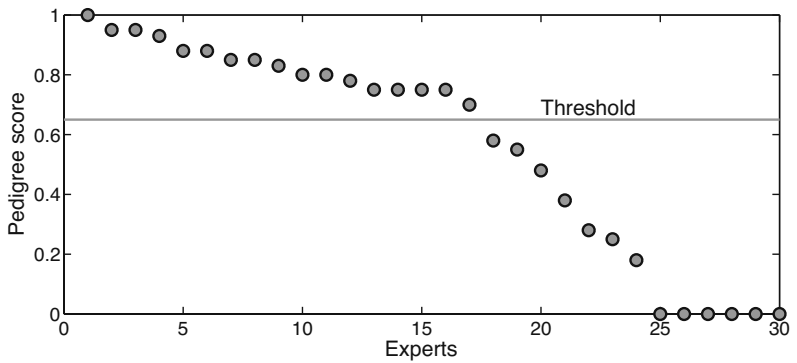


these experts have enough experience with the WAQUA model to reliably give estimates of its uncertainty.

\subsection{Identification of Uncertainties}

The uncertainties are identified following the locations (first dimension) according to Walker et al. (2003). Walker et al. (2003) describe five possible locations of uncertainty: a) context uncertainty, including uncertainties that are located outside the model boundary and relate to the assumptions and choices underlying the model, b) input uncertainty, c) model uncertainty, which consists of model structure uncertainty and model technical uncertainty, d) parameter uncertainty, and e) uncertainty in the model outcomes. The levels of uncertainty (second dimension) range from statistical uncertainty and scenario uncertainty through recognized ignorance to total ignorance. For the last dimension, the nature, they distinguish between epistemic uncertainty (due to a lack of knowledge) and variability uncertainty (due to the variability in the behavior of the natural, social, economic or technical system).

The first step in the identification of uncertainties is to elicit a global list of uncertainties. This is done by asking the experts, which uncertainties play a role in this case study. By considering all locations of uncertainty, including model context and model structure the global list with identified uncertainties will be more complete than if only uncertainties in input and parameters are taken into account.

The next step is to go through this list again and check if the identified uncertainties are unique and complementary (Warmink et al. 2010). To assure this, every uncertainty needs to be described accurately and specified along all three dimensions in a unique manner. This methodology is presented in Warmink et al. (2010). In this step of the identification, we attempt to classify the listed uncertainties from the first step into a single class for each dimension. This means that an uncertainty can, for instance, not be at the level of 'statistical uncertainty' and 'scenario uncertainty' at the same time. If the uncertainty falls into two classes of any dimension, the uncertainty needs to be broken down into smaller parts and described in more detail. This methodology assures that the resulting uncertainties are unique and form a consistent set.

\subsection{Aggregation of Expert Opinions}

The aggregation of expert opinions for the drafting of probability distributions of model input and model parameters for Monte Carlo analysis, brings several important methodological difficulties (Van der Sluijs 1997). Firstly, the fraction of the experts having a certain view is not proportional to the probability of that view to be correct. This implies that the spreading in the expert opinions can not be used to describe the uncertainty and as a result the expert opinions cannot be averaged. However, Cooke and Goossens (2000) state that if appropriate weights are given to the experts, averaging can be conducted. Also, Keith (1996) states that averaging of expert opinions can be safely conducted, but only if the experts refer to the same model. In expert opinion practice, this is hardly the case (Keith 1996). Weighting and combining the individual estimates of distributions is only valid if the opinions are weighted with competence of the experts making the estimate. To account for 
the above mentioned difficulties, the experts are given a weight using the Pedigree scores to be able to average the experts estimates.

\subsection{Interviews}

In a face-to-face interview of approximately one hour, the experts were asked to indicate the parts of the model that had the most influence on the uncertainty of the model outcomes. This means that either an uncertainty has a high degree of uncertainty itself, or it has a large influence on the model outcomes, or both. This question was asked for the computation of the design water levels (DWL), and for the computation of the effects of measures taken in the river bed. This resulted in two (partly overlapping) lists with uncertainties.

For each list, the uncertainties were broken down into uncertainties with an equal level of detail, using the classification matrix by Walker et al. (2003). Next, the experts have been asked to identify the major sources of uncertainty. In many cases these uncertainties overlapped between the different experts. However these lists were not comparable, because some experts mentioned the small (negligible) uncertainties, while other experts omitted these uncertainties. Therefore, it was not possible to compare the number of times a source of uncertainty was mentioned.

Furthermore, the experts were asked to comment on each uncertainty and to give a value for the contribution of that uncertainty to the uncertainty in model outcomes in terms of water levels. The uncertainty is therefore expressed as a value that represents the maximum uncertainty range, which ranges from plus or minus the given value. For an effect study the uncertainty was expressed as a percentage of the effect. For example, if a floodplain excavation of $1 \mathrm{~m}$ has an effect of $10 \mathrm{~cm}$ on the water level on the river axis and the uncertainty was chosen to be $50 \%$, this means that the effect of this excavation lies between 5 and $15 \mathrm{~cm}$.

In many cases the experts were not able to give a single number for the uncertainty. Sometimes a range was given or an order of magnitude (millimeters, centimeters, or decimeters). In case an expert mentioned a range in which the value of the uncertainty was located, the average of that range was taken for further analysis. If the experts were not able to give a numerical value, sometimes they expressed the uncertainty in qualitative terms, such as "small" and "large". Other experts were not able to give any value at all. No guidance was given how to interpret the terms "large" or "small", so the experts made their own subjective judgment in this respect. The experts identified 16 different sources of uncertainty for both applications of the WAQUA model. For each source of uncertainty, a maximum of 5 experts were able to quantify the uncertainty.

\section{Results}

\subsection{Identification of Uncertainties in Design Water Levels}

Each expert identified at least seven different uncertainties. The identified uncertainties are shown in Table 2. The uncertainties in this table are sorted with decreasing importance according to the weighted average of the expert opinions. The terms measurements, schematization, discretization and formulation are used to denote the 
Table 2 Identified sources of uncertainty in design water levels

\begin{tabular}{|c|c|c|}
\hline ID & Short name & Description \\
\hline 1 & Upstream discharge & $\begin{array}{l}\text { Discharge that is imposed as upstream discharge. The design } \\
\text { discharge is derived by extrapolation of a historical } \\
\text { discharge series. Subsequently, a design discharge wave } \\
\text { is constructed with a return period of } 1250 \text { years }\end{array}$ \\
\hline 2 & $\mathrm{MC}$ roughness predictor & The empirical roughness predictor for the main channel \\
\hline 3 & Vegetation schematization & The schematization of the vegetation in the floodplain area \\
\hline 4 & Weir formulation & $\begin{array}{l}\text { The formulation of the energy losses, due to acceleration and } \\
\text { deceleration of the water flow over weirs, embankments or } \\
\text { slopes in the landscape }\end{array}$ \\
\hline 5 & Calibration data & $\begin{array}{l}\text { The data used for the calibration of the model. This data } \\
\text { consists of measured water levels and discharges, both of } \\
\text { which are uncertain }\end{array}$ \\
\hline 6 & MC bathymetry discretization & $\begin{array}{l}\text { Discretization of the measurements of the main channel } \\
\text { bathymetry onto the computational grid }\end{array}$ \\
\hline 7 & FP roughness predictor & $\begin{array}{l}\text { Empirical roughness equation for the floodplain vegetation } \\
\text { and other objects in the floodplain area }\end{array}$ \\
\hline 8 & FP vegetation measurements & $\begin{array}{l}\text { Measurements of the floodplain vegetation. This represents } \\
\text { the variability within the floodplain ecotopes and the } \\
\text { accuracy of the classification }\end{array}$ \\
\hline 9 & Weir discretization & The discretization of the weirs on the computational grid \\
\hline 10 & MC bathymetry measurements & Measurements of the bathymetry of the main channel \\
\hline 11 & FP bathymetry measurements & Measurements of the bathymetry of the floodplain area \\
\hline 12 & Eddy viscosity & $\begin{array}{l}\text { Eddy viscosity parameter that accounts for energy losses } \\
\text { due to velocity differences }\end{array}$ \\
\hline 13 & SWE discretization & Numerical method to discretize the shallow water equations \\
\hline 14 & Discharge distribution & $\begin{array}{l}\text { Distribution of the discharge over the three branches of the } \\
\text { river Rhine }\end{array}$ \\
\hline 15 & Groyne formulation & $\begin{array}{l}\text { The method that is used to compute the energy losses due } \\
\text { to groynes }\end{array}$ \\
\hline 16 & Season of peak discharge & $\begin{array}{l}\text { Currently, it is assumed that a peak discharge will occur in } \\
\text { winter when the vegetation has no leafs. However, if a peak } \\
\text { discharge occurs in spring the circumstances, especially of } \\
\text { the vegetation, are different }\end{array}$ \\
\hline
\end{tabular}

$F P$ represents floodplain and $M C$ represents main channel. The uncertainties are sorted by decreasing uncertainty according to the average quantified expert opinions

different steps in the setup of the model. Firstly, the uncertainty due to measurements is caused by the measurement instrument and measurement method in the field. Secondly, the schematization represents the method that is used to translate the measurements to different classes that are used in the model. For example, the schematization of the vegetation is the decision in which of the three classes of forest an observed forest would fit best. This depends on the type of trees, the average tree-height and the density of the trees in the forest. Next to these data, also the actual average density of the trees in the forest is an input parameter. The vegetation manual (Van Velzen et al. 2003) is used as the guideline to discriminate the different vegetation classes. Thirdly, the discretization represents the method that is used to discretize, for example, the vegetation classes onto a grid. The uncertainty is caused by the delineation of these observed vegetation patches and depends on the grid size. 
Fig. 3 Number of expert opinions for each source of uncertainty for the design water level case. Specified as mentioned uncertainties, qualified uncertainties or quantified uncertainties. The numbers on the horizontal axis refer to the uncertainty ID's listed in Table 2

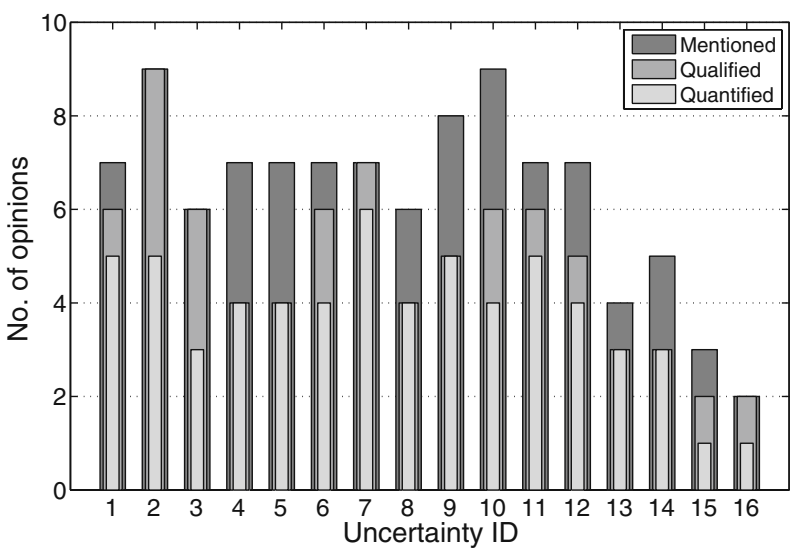

Finally, the uncertainty due to formulation stems from the structure of the equation that is used in the model.

\subsection{Quantification of Uncertainties in Design Water Levels}

Figure 3 shows the number of times an uncertainty is mentioned by an expert compared to the number of times an uncertainty is qualified and quantified. The values are given cumulative, which means that every quantified uncertainty is assumed qualified and, of course, mentioned. This figure shows that almost all uncertainties are mentioned equally often and most uncertainties are quantified by more than four experts. Uncertainties 15 and 16 both are only quantified by one expert, but they stated this uncertainty as very uncertain, therefore these were included in the analysis. The results from the uncertainties that were mentioned by only one or two expert were considered to be not important and are not shown.

Figure 4 shows only the opinions of the experts that were able to quantify the uncertainty. The left panel of this figure shows that the sources of uncertainty number 1 and 2, upstream discharge and main channel roughness predictor have the largest contribution to the uncertainty in the model outcomes. Both the weighted average and the maximum value given by an expert are large compared to the other uncertainties. The range of the individual expert opinions for the upstream discharge

Fig. 4 Quantitative results of the expert opinions for the design water level case. Average (+ symbols) and individual expert opinions (open circles) are shown. Note the difference in the scale of the vertical axes. The numbers on the horizontal axis refer to the uncertainty ID's listed in Table 2
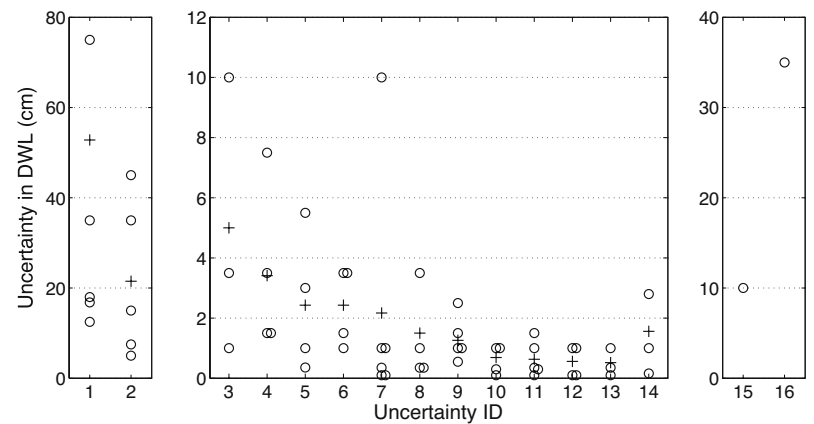
lies between 12.5 and $75 \mathrm{~cm}$ for the computed water levels under design conditions. The uncertainty due to the main channel roughness predictor ranges between 5 and $35 \mathrm{~cm}$. Additionally, one expert states that the upstream discharge has a "large" influence on the design water levels (see Fig. 5). Furthermore, three experts state that the main channel roughness equation has a "large" contribution to the uncertainty in the design water levels.

The center panel of Fig. 4 shows that the sources of uncertainty 3-6 result in an average uncertainty between 5 and $2 \mathrm{~cm}$ in the computed water level. These uncertainties clearly have a smaller contribution than uncertainties 1 and 2, but still are considered to be important. For the sources of uncertainty 7 and 8 , only one expert has the opinion that the uncertainty is larger than $2 \mathrm{~cm}$. None of the experts have the opinion that uncertainties 9-14 have an uncertainty larger than $3.5 \mathrm{~cm}$. Therefore, these uncertainties are considered to be not important. As a first step, these uncertainties can be excluded from an uncertainty analysis. In the computation of the Hydraulic Boundary conditions the computed water levels are usually rounded on $5 \mathrm{~cm}$. Therefore, uncertainties below this threshold are considered not important. However, the cumulative contribution of these uncertainties can be significant. Also, non-linear effects in the model may have the result that these uncertainties have a larger contribution to the uncertainty in the model outcomes.

Uncertainties 15 and 16 (groyne formulation and the season of high discharge) in the right panel of Fig. 4 are mentioned by one expert only. Therefore, it is not possible to say anything about the average uncertainty and its importance. However, both uncertainties are qualified as important. Therefore, it is possible that these uncertainties have a large contribution to the uncertainty in the model outcomes. Future study on these uncertainties is therefore required.

Some experts were not able to express the uncertainty in a value. They expressed the uncertainty for a certain source qualitatively as "large" or "small". Figure 5 shows these results. It must be noted that these opinions do not overlap the quantified uncertainties. For each uncertainty the number of times the uncertainty was qualified as "large" or "small" is shown. This figure shows the same trend as the quantified results. The uncertainties 1-3 were considered more often as "large" than as "small". Furthermore a trend of decreasing uncertainty is shown with increasing uncertainty number, because the uncertainties are sorted on their quantified average values. This indicates that the qualitative results show the same behavior as the quantified uncertainties. The uncertainty in the season of peak discharge is also considered "large" in addition to the value of $35 \mathrm{~cm}$ estimated by one other expert. This may be an indication that this might be an important source of uncertainty. The similarity between the qualitative and quantitative results increases the confidence in the quantified uncertainties.

Fig. 5 Qualitative results of the expert opinions for the design water level case. The numbers on the horizontal axis refer to the uncertainty ID's listed in Table 2

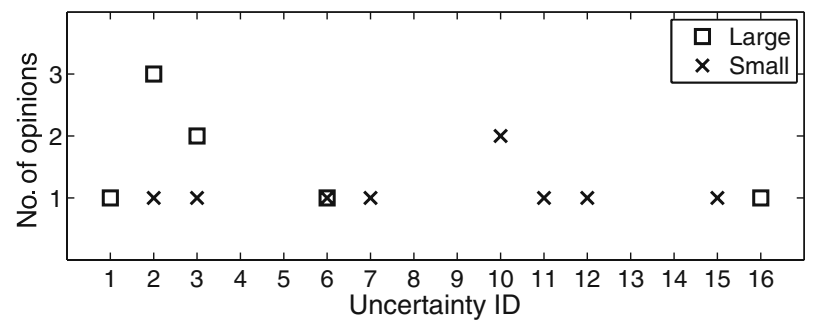




\subsection{Identification of Uncertainties in Effect Studies}

Table 3 summarizes the identified uncertainties in the computation of effect studies. Only the largest eight uncertainties are shown. The experts identified in total 18 different uncertainties. Next to the uncertainties in Table 3 they mentioned, for example, the choices made by the modeller, the eddy viscosity parameter and the measurements of the main channel bathymetry as uncertainties. However, these uncertainties could not be quantified and only qualified by one or two experts. For clarity, these results are not shown in the analysis. However, in addition to these uncertainties the natural succession of vegetation is mentioned by four experts as a large uncertainty. This uncertainty however could not be quantified and is therefore omitted from this list as well.

\subsection{Quantification of Uncertainties in Effect Studies}

Figure 6 shows that about half of the experts that mentioned an uncertainty were able to quantify it. Furthermore, more uncertainties are mentioned and quantified

Table 3 Identified sources of uncertainty in effect studies

\begin{tabular}{|c|c|c|}
\hline ID & Short name & Description \\
\hline 1 & Schematization FP vegetation & $\begin{array}{l}\text { The schematization of the vegetation in the floodplain area. } \\
\text { This source of uncertainty comprises the uncertainty } \\
\text { in the measurements and the uncertainty due to the } \\
\text { variability within each class of vegetation }\end{array}$ \\
\hline 2 & Groyne formulation & $\begin{array}{l}\text { The groyne formulation is uncertain, because groynes } \\
\text { are modeled as weirs. Therefore, amongst others, the } \\
\text { 3D effects around the tip of the groynes are ignored }\end{array}$ \\
\hline 3 & FP bathymetry measurements & Measurements of the bathymetry in the floodplain area \\
\hline 4 & Weir schematization & $\begin{array}{l}\text { The schematization of the weirs is uncertain. This is caused } \\
\text { by the uncertainties in the measurements in the heights of } \\
\text { the weirs. Also, steep slopes in the floodplain area are } \\
\text { computed by means of a weir formulation if the slope } \\
\text { is above a certain threshold. This causes that energy losses } \\
\text { due to some slopes are computed as weirs, while energy } \\
\text { losses due to smaller slopes in the landscape are omitted } \\
\text { Furthermore, the slopes classified as weirs are then } \\
\text { assumed to have a fixed slope }\end{array}$ \\
\hline 5 & Weir formulation & $\begin{array}{l}\text { Formulation of the energy losses, due to acceleration and } \\
\text { deceleration of the water flow over weirs. The equation } \\
\text { used for these weirs is empirically derived }\end{array}$ \\
\hline 6 & FP roughness equation & $\begin{array}{l}\text { Empirical roughness equation that computes the energy } \\
\text { losses due to vegetation and other objects in the } \\
\text { floodplain area }\end{array}$ \\
\hline 7 & $\begin{array}{l}\text { Discretization FP bathymetry } \\
\text { and vegetation }\end{array}$ & Discretization of the bathymetry and vegetation onto a grid \\
\hline 8 & Discharge distribution $\mathrm{FP}-\mathrm{MC}$ & $\begin{array}{l}\text { The discharge distribution between the floodplain an the } \\
\text { main channel }\end{array}$ \\
\hline
\end{tabular}

$F P$ represents floodplain and $M C$ represents main channel. The uncertainties are sorted by decreasing uncertainty according to the average quantified expert opinions 
Fig. 6 Number of expert opinions for each source of uncertainty for the effect studies case. Specified as mentioned uncertainties, qualified uncertainties or quantified uncertainties. The numbers on the horizontal axis refer to the uncertainties listed in Table 3

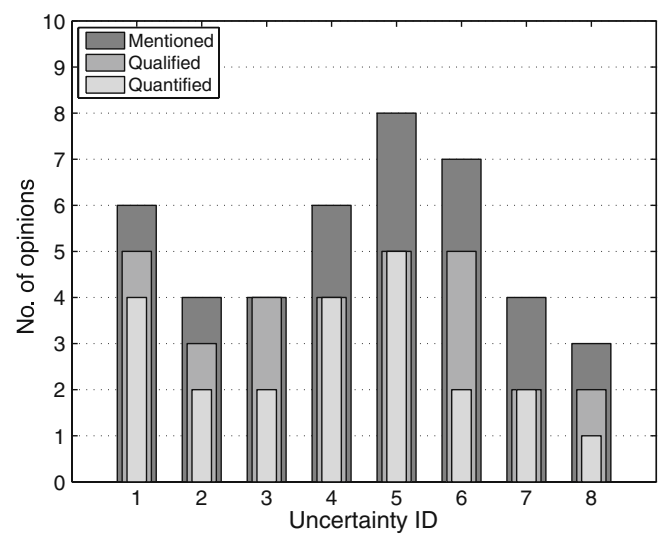

for the design water level computations than for the effect study computations. The ranking in the sources of uncertainty in effect studies is less pronounced.

The uncertainties are quantified by the experts as a percentage of the computed effect on the water level in the river of a measure taken in the river bed. Figure 7 shows the individual expert opinions and the weighted average for each uncertainty that the experts were able to quantify. The uncertainty that causes the largest uncertainty in the computed effect is the discharge distribution over the floodplain and the main channel. However, this source of uncertainty is actually a variable within the model, which is the result of the ratio of the aggregated roughness between the floodplain and the main channel. The weighted average due to the schematization of floodplain vegetation, is larger than the other values. However, no clear distinction in the weighted averages is visible between the sources of uncertainty.

Figure 8 shows that for each of the uncertainties 1-3, one additional expert qualified the uncertainty as "large". For uncertainty 7 one expert qualified it as "large", while two experts qualified it as "small". For the effect studies case, the quantitative and the qualitative results both show no clear distinction between the different uncertainties. Next to these listed uncertainties, four experts identified the natural succession of the floodplain vegetation as an additional uncertainty with

Fig. 7 Quantitative results of the expert opinions for the effect studies case. Average $(+$ symbols $)$ and individual expert opinions (open circles) are shown. The numbers on the horizontal axis refer to the uncertainty ID's listed in Table 3

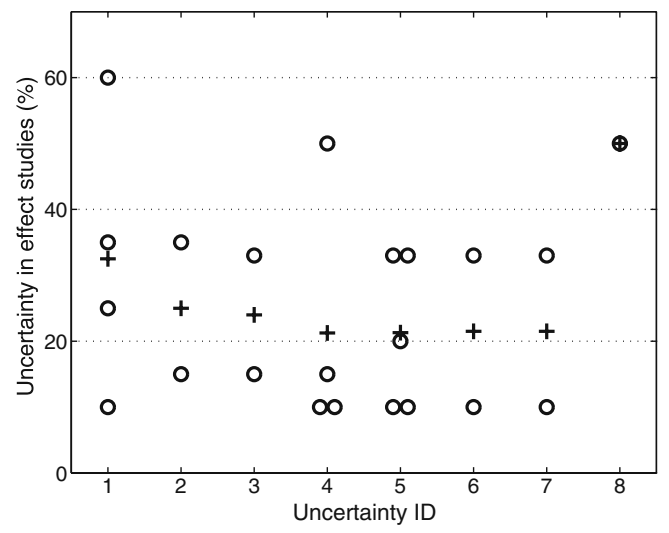


Fig. 8 Qualitative results of the expert opinions for the effect studies. The numbers on the horizontal axis refer to the uncertainties listed in Table 3

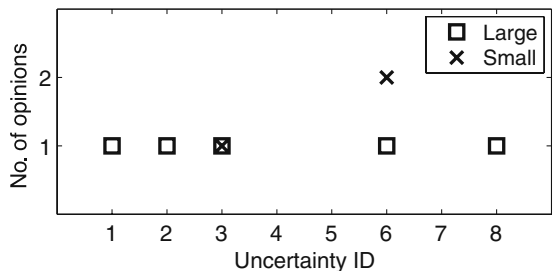

a "large" contribution. However, no expert was able to quantify the contribution of this source of uncertainty to the effect on the computed water levels.

The uncertainties in the effect studies case are more difficult to quantify than the uncertainties in the DWL case, because the uncertainty highly depends on local circumstances. Local circumstances are, for instance, the local topography of a floodplain due to the construction of a small channel or the vegetation characteristics of a floodplain. The experts gave generic statements to qualify the uncertainty for a given situation. Firstly, if a characteristic of the floodplain in the modeled region is changed between the two model runs, it might be important. For example, if the effect of a small channel in the floodplain is modeled this channel is included in the schematization. The uncertainty in the schematization of that channel can be very important. However, if this channel was already in the schematization, the uncertainty might not be important. In general, the experts stated that characteristics that do not change between two model runs generally have little contribution to the uncertainty. Furthermore, if a characteristic of the modeled region is also in a region with large flow, this uncertainty could have a large contribution to the model outcome uncertainty. The locations with a large flow are locally highly variable. The experts stated that if a part of the floodplain has a large discharge capacity and therefore a large flow, the uncertainties in that part of the floodplain are more important than in low flow regions. Therefore, quantification of individual sources is only possible for a specific situation if all other uncertainties are assumed deterministic. Especially for the effect studies case, there is a strong correlation between the sources of uncertainty and the flow field, because uncertainties are highly sensitive to that flow field.

\section{Discussion}

Firstly, the influence of calibration on the answers given by the experts is addressed, because it was often mentioned in the interviews as a complication of the uncertainty assessment. Secondly, the different sources of bias in expert opinion research are discussed that may have played a role in this study. Finally, the aggregation of the expert opinions and the methodology that was used during the elicitation of the expert opinions is discussed.

\subsection{Calibration}

Calibration plays an important role in the quantification of the sources of uncertainties. The method used to calibrate the WAQUA model for the DWL computations and effect studies case is described in Section 2. According to the experts many 
uncertainties are reduced by calibration. This effect is taken into account in the experts' estimation of the uncertainties. The uncertainties that are influenced by calibration are uncertainties in the measurement data, uncertainties in the discretization of these data onto a grid and the uncertainties in the computational parameters, such as the eddy viscosity, because it is assumed that these parts of the model do not change between the situation used during calibration and the design conditions. For example, the experts state that for a floodplain that has the same topography and vegetation in 1995 and in 2006, the uncertainty in the topography is reduced by calibration, because all errors that are compensated by the calibration on the 1995 case are still compensated in the 2006 case if nothing has changed. However, the interactions between the flow through the floodplain and a small dike that did change between the two schematizations, might have an effect on the uncertainty.

The uncertainties that are not compensated for by calibration are valued by the experts to have a larger contribution to the uncertainty in the model outcomes for the DWL case. These uncertainties comprise the upstream discharge and the main channel roughness formulation. Furthermore, some experts stated that the extrapolation from the calibrated situation to design conditions also introduces uncertainty in other parts of the model. This uncertainty mainly comes from the difference in water levels between the calibration conditions and the design conditions. This difference is especially large in the floodplain area and becomes apparent in the roughness formulations. Therefore, the floodplain roughness formulation and the weir formulation are also stated as uncertain. For example, some experts question the validity of the weir formulation in the case that a large water level is present above the top of the weir.

The major difficulty in the determination of the main uncertainties is that all uncertainties are correlated. Therefore, many experts state that the discharge distribution between the floodplain and the main channel is of main importance. The ratio between both discharges expresses the ratio between the aggregated roughness of the main channel and the aggregated roughness of the floodplain area. In future studies, this characteristic should be taken into account in the calibration and validation of $2 \mathrm{D}$ hydrodynamic models. The uncertainty in this characteristic also expresses the uncertainty in the aggregated roughnesses.

\subsection{Expert Bias}

Experts opinion research is known to have several difficulties. One has to cope with judgmental heuristics and the biases, which are produced in the expert opinions (Van der Sluijs et al. 2004). Sources of bias are: anchoring, availability, coherence, representativeness, satisficing, overconfidence and motivational bias (Van der Sluijs et al. 2004). These sources of biases are discussed in the next paragraphs.

Anchoring is the bias of experts to weigh their opinions towards the conventional value or the first given value. In this study, most experts refer to previous research that is known to the expert. For example, the experts frequently refer to the research reports of Stijnen et al. (2002) and Ogink (2003). Also, unpublished memos and other small studies are the sources of the experts opinions. Therefore, also availability bias plays a role in the results by giving too much weight to the available data. These reports and memos are assumed to give a good approximation of the uncertainties, because the aim of their studies was to give an overview of some of the important 
uncertainties. However, these reports and memos only focused on a limited number of uncertainties. Also, these documents are not easily available and only the involved experts know of their existence.

Coherence bias means that events are considered more likely if many scenarios can be created that lead to an event, or if some scenarios are particularly coherent (Van der Sluijs et al. 2004). In this study coherence bias did not play a role, because only a single scenario was considered. Representativeness bias is caused by placing confidence in a single piece of information that is considered to represent a larger process and satisficing bias refers to the tendency to search through a limited number of solutions and select the most appropriate. In this study these sources of bias have little influence on the results, because the case study was strongly framed by the specific model and the experts were asked to indicate which part of this model was uncertain and to quantify this uncertainty. Therefore, the list of options was considered equal for all experts.

Overconfidence is that experts tend to over estimate their ability to make quantitative judgments. This bias is difficult for an individual to guard against (Van der Sluijs et al. 2004) and probably played a role in this study. Overconfidence may result in too narrow uncertainty bands (Cooke 1991). The effect of overconfidence in this study is that the stated uncertainties may be smaller than the actual uncertainties. The uncertainties are therefore considered to be on the lower end of the "true" uncertainty.

Motivational bias probably was important during the interviews. The experts all had their own area of expertise. For example, some experts had most experience with the input data used for the model. These experts had the tendency to give most uncertainty to the part of the model with which they were most familiar. In this study, there is no indication that a certain part of the model is better represented by the experts than other model parts. This gives confidence that most important uncertainties are represented by several of the experts. This is shown in Figs. 3 and 6 in which uncertainties 1-12 for the DWL are mentioned all approximately seven times, also the uncertainties for the effect studies are mentioned approximately seven times. Thereby, it is assumed that experts who were not familiar with a certain topic omitted the uncertainty or stated a small value. This also has the effect that the average uncertainties are biased towards the lower end.

Furthermore, analysis of the results shows that there is a weak correlation $\left(\mathrm{R}^{2}=0.22\right)$ between the Pedigree scores of the experts and the average quantified uncertainty. This indicates that the experts with more expertise do not give higher or lower estimates of the uncertainty. Also, a weak correlation was found between the high uncertainties and the experts. So, we may safely state that high values of the uncertainty cannot be attributed to one or a few experts only. The maximum values for the uncertainties are stated by different experts, which means that most experts do not agree, which uncertainty is most important. However, the weighted average values for the DWL case show that some uncertainties are more important.

\subsection{Aggregation of Expert Opinions}

Aggregations of expert opinions are prone to bias from the selection of experts and to the creation of the impression of consensus where none exists (Krayer von Krauss et al. 2004). However, to facilitate the comparison of experts the weighted average of 
the values given by the experts is taken. It is not attempted to present the values as single truth, but merely as an order of magnitude, which is similar to the significance of the experts opinions. Nor is it attempted to give the impression of consensus among experts. However, the discussion of biases in expert opinion elicitation above indicates that the the elicited uncertainties are more likely to be on the lower end of the "true" uncertainty.

The discussion of the appropriateness of aggregating expert opinions has a long history; see for example Cooke (1991) and Rowe (1992). In the discussion there are two camps, those who consider aggregation of expert opinion absurd and those who do not. Krayer von Krauss et al. (2004) and Keith (1996) have the opinion that the appropriateness depends on the individual circumstances and what is meant to be accomplished. Due to the objective selection of experts, the equal levels of detail of the uncertainties, the framed case study, and the aim to compare the uncertainties relatively to each other, we argue that in this case, averaging of expert opinions is valid.

We have shown that in accordance with Van der Sluijs et al. (2005b) and Krayer von Krauss et al. (2004) expert opinion elicitation can be a good method to identify and, to a certain degree, quantify uncertainties. Including expert opinions in an uncertainty analysis is valuable in the first steps of an uncertainty analysis. Experts were able to identify, rank and quantify to a certain degree the uncertainties in the model outcomes of the WAQUA model. The main difference with the studies by Van der Sluijs et al. (2005b) and Krayer von Krauss et al. (2004) is that we use an objective method to select the experts. This gives confidence that the outcomes of the expert interviews are reliable, because the results of an expert opinion study are sensitive to the selection of the experts (Van der Sluijs 1997).

The interviews with the experts have been conducted individually, which gives a good representation of the expert opinions and is good for the identification of the uncertainties by the experts. It is recommended to organize a workshop with all elicited experts to discuss the results and try to reach a consensus. However, in this study it was not possible to organize the workshop, due to time limitations. If consensus is reached during a workshop that will make the results more reliable and it can be used to further specify and quantify the uncertainties in the model outcomes.

The first objective of this study was to identify the different uncertainties the WAQUA model for the DWL and effect studies case. Tables 2 and 3 show that for both cases the uncertainties are identified. By comparing the uncertainties stated by the different experts to each other clearly identified sources of uncertainty become clear. The distinction between the different uncertainties is strengthened by the quantification, because for the quantification the uncertainties need to be well-framed and unambiguous. The ranking of the uncertainties from important to less important is strengthened by the combination of qualitative and quantitative information about the uncertainties.

Figure 4 shows that the weighted average values of the uncertainties have the same trend as the maximum values. Also, the relative spreading in the expert opinions (the maximum minus the minimum divided by the average) has a constant value of approximately 2 with a decrease in the average value for the uncertainty. This suggests that the weighted average value gives the correct trend in the experts opinions. Therefore, we argue that it is valid to use the weighted average to aggregate 
the expert opinions with the note that the average values can only be compared relatively and no consensus among the experts is suggested.

For the effect studies case, the quantitative and the qualitative results (Figs. 7 and 8 ) both show no clear distinction between the different uncertainties. This is because for effect studies the uncertainties are dominated by local circumstances and the local flow field. However, the experts stated that all uncertainties are in the order of magnitude of $25 \%$ of the computed effect. Therefore, this can be considered a good approximation of the uncertainties in effect studies computations. Furthermore, the uncertainties are dominated by the method to formulate, schematize and discretize weirs, bathymetry and vegetation. Therefore, to reduce the uncertainties in effect studies, these uncertainties need to be further addressed.

In this study we quantified the uncertainties in the outcomes of a two dimensional river model for different sources of uncertainties in the model. Although it is not possible to give exact values for the uncertainty, the order of magnitude of the uncertainty due to different sources can be determined. We want to stress that it is not attempted to present the values as single truth, but merely as an order of magnitude, which is similar to the significance of the experts opinions.

We attempted to quantify the uncertainty of the different sources themselves, which is needed as input for an uncertainty propagation analysis. However, the experts were not able to give a reliable estimate for the uncertainty of the different sources. Therefore, in a future study, the uncertainties in the DWL and effect studies case that have a large influence on the model outcomes, need to be quantified. For example, the experts were not able to give an uncertainty range for the roughness in the main channel. This is due to the fact that the hydraulic roughness is not a truly physical parameter, but it is lumped and therefore, the experts cannot give reliable estimates. In a future study we will address this issue and try to quantify the uncertainty in the most important parts of the model. Subsequently, this uncertainty is propagated through the model to yield the uncertainty of the computed water levels. These results will be compared to the experts opinions.

\section{Conclusion}

The aim of this study was to identify the sources of uncertainty that contribute most to the uncertainties in the model outcomes and quantify their contribution to the uncertainty in the model outcomes. The experts stated that the sources of uncertainties are different for the computation of the design water levels and effect studies. In the design water level computations case, the uncertainties were dominated by the sources that do not change between the calibration and the prediction. The results from the experts opinions showed that the upstream discharge and the empirical roughness equation for the main channel contribute most to the uncertainty in the design water levels. It was not possible to give exact values for the uncertainty, however, the order of magnitude of the uncertainty due to different sources of uncertainty could be determined.

Furthermore, the ranking of the uncertainties from important to less important was strengthened by the combination of qualitative and quantitative information about the uncertainties. For effect studies, the floodplain bathymetry, weir formulation and discretization of floodplain topography induces the largest uncertainty. 
However, the ranking for the effect studies case was less clear than for the design water level case, because the uncertainties for effect computations are dominated by the local flow field. The use of a Pedigree analysis assures an objective selection of experts and gives confidence that the outcomes of the expert interviews are reliable.

The contribution of the uncertainties to the model outcomes show that the uncertainties have a significant effect on the predicted water levels under design discharge conditions and for effect studies. The experts were not able to quantify the uncertainties themselves, only the contribution to the model outcomes. Future research focuses on the quantification of the most important uncertainties and on the propagation of these uncertainties to the model outcomes.

Acknowledgements This research is supported by the Technology Foundation STW, and the technology program of the Ministry of Economic Affairs. The authors thank all experts for their time and constructive input in the preparation stage and during the interviews.

Open Access This article is distributed under the terms of the Creative Commons Attribution Noncommercial License which permits any noncommercial use, distribution, and reproduction in any medium, provided the original author(s) and source are credited.

\section{References}

Ayyub BM (2001) Elicitation of expert opinions for uncertainty and risks. CRC Press, Florida, USA, ISBN 0-8493-1087-3

Bates PD, Horritt MS, Aronica G, Beven KJ (2004) Bayesian updating of flood inundation likelihoods conditioned on flood extent data. Hydrol Process 18(17):3347-3370. doi:10.1002/hyp.1499

Cooke RM (1991) Experts in uncertainty. Oxford University Press, Oxford, UK, ISBN 0-19-506465-8

Cooke RM, Goossens LHJ (2000) Procedures guide for structured expert judgement in accident consequence modelling. Radiat Prot Dosim 90(3):303-309

Funtowicz SO, Ravetz JR (1990) Uncertainty and quality in science for policy. Theory and decision library, series A, philosophy and methodology of the social sciences. Kluwer, Dordrecht, The Netherlands, ISBN 0-7923-0799-2

Groenenberg H, Van der Sluijs JP (2005) Valueloading and uncertainty in a sector-based differentiation scheme for emission allowances. Clim Change 71(1-2):75-115. doi:10.1007/ s10584-005-5376-7

Hall JW, Solomatine D (2008) A framework for uncertainty analysis in flood risk management decisions. Journal of River Basin Management 6(2):85-98

Hall JW, Tarantola S, Bates PD, Horritt MS (2005) Distributed sensitivity analysis of flood Inundation model calibration. J Hydraul Eng 131(2):117-126. doi:10.1061/(ASCE)0733-9429 (2005)131:2(117)

Hunter NM, Bates PD, Horritt MS, Wilson MD (2007) Simple spatially-distributed models for predicting flood inundation: a review. Geomorphology 90(3-4):208-225. doi:10.1016/ j.geomorph.2006.10.021

Johnson PA (1996) Uncertainty in hydraulic parameters. J Hydraul Eng 122(2):112-114

Keith DW (1996) When is it appropriate to combine expert judgements? Clim Change 33(2):139-144. doi:10.1007/BF00140244

Krayer von Krauss MP, Casman EA, Small MJ (2004) Elicitation of expert judgments of uncertainty in the risk assessment of herbicide-tolerant oilseed crops. Risk Anal 24(6):1515-1527. doi:10.1111/j.0272-4332.2004.00546.x

Leendertse JJ (1967) Aspects of a computational model for long-period water-wave propagation. Ph.D. thesis, RM-5294-RR, Rand Corporation, Santa Monica, USA

Ministry of Transport, Public Works and Water Management (1995) Flood protection act. Ministry of Transport, Public Works and Water Management, The Hague, The Netherlands (in Dutch)

Morgan MG, Henrion M (1990) Uncertainty: a guide to dealing with uncertainty in quantitative risk and policy analysis. Cambridge University Press, Cambridge, UK, ISBN 0-521-36542-2 
Ogink HJM (2003) Nauwkeurigheid toetspeilen. Tech. rep. Q3634, WL | Delft Hydraulics, Delft, The Netherlands (in Dutch)

Pappenberger F, Beven KJ, Horritt MS, Blazkova S (2005) Uncertainty in the calibration of effective roughness parameters in HEC-RAS using inundation and downstream level observations. J Hydrol 302(1-4):46-69. doi:10.1016/j.jhydrol.2004.06.036

Refsgaard JC, Van der Keur P, Nilsson B, Müller-Wohlfeil D, Brown J (2006a) Uncertainties in river basin data at various support scales - example from Odense pilot river basin. Hydrol Earth Syst Sci Discuss 3(4):1943-1985

Refsgaard JC, Van der Sluijs JP, Brown J, Van der Keur P (2006b) A framework for dealing with uncertainty due to model structure error. Adv Water Resour 29(11):1586-1597. doi:10.1016/j.advwatres.2005.11.013

Rijkswaterstaat (2007) Hydraulische randvoorwaarden primaire waterkeringen, voor de derde toetsronde 2006-2011 (HR 2006). Tech. rep., Ministry of Transport, Public Works and Water Management, The Netherlands (in Dutch)

Rijkswaterstaat (2009) User's Manual WAQUA, versie 10.97. Rijkswaterstaat, The Netherlands (in Dutch)

Rowe G (1992) Perspectives on expertise in the aggregation of judgments. Springer, US, Chap 7, pp 155-180, ISBN 978-0-306-43862-2

Stijnen JW, Kok M, Duits MT (2002) Onzekerheidsanalyse hoogwaterbescherming Rijntakken. Tech. rep. PR464, HKV Lijn in water/Rijkswaterstaat, The Netherlands (in Dutch)

Van den Brink NGM, Beyer D, Scholten MJM, Van Velzen EH (2006) Onderbouwing hydraulische randvoorwaarden 2001 voor de Rijn en zijn takken. Tech. rep. 2002.015, Rijkswaterstaat, The Netherlands ISBN 90-3695-322-7 (in Dutch)

Van der Keur P, Henriksen HJ, Refsgaard JC, Brugnach M, Pahl-Wostl C, Dewulf A, Buiteveld H (2008) Identification of major sources of uncertainty in current IWRM practice. Illustrated for the Rhine basin. Water Resour Manage 22(11):1677-1708. doi:10.1007/s11269-008-9248-6

Van der Keur P, Brugnach M, DeWulf A, Refsgaard JC, Zorilla P, Poolman M, Isendahl N, Raadgever GT, Henriksen HJ, Warmink JJ, Lamers M, Mysiak J (2010) Identifying uncertainty guidelines for supporting policy making in water management illustrated for Upper Guadiana and Rhine basins. Water Resour Manage. doi:10.1007/s11269-010-9640-x

Van der Klis H (2003) Uncertainty analysis applied to numerical models of bed morphology. Ph.D. thesis, Delft University of Technology, Delft, The Netherlands

Van der Sluijs JP (1997) Anchoring amid uncertainty, on the management of uncertainties in risk assessment of anthropogenic climate change. Ph.D. thesis, Utrecht University, Utrecht, The Netherlands

Van der Sluijs JP (2002) A way out of the credibility crisis of models used in integrated environmental assessment. Futures 34(2):133-146. doi:10.1016/S0016-3287(01)00051-9

Van der Sluijs JP (2007) Uncertainty and precaution in environmental management: insights from the UPEM conference. Environ Model Softw 22(5):590-598. doi:10.1016/j.envsoft.2005.12.020

Van der Sluijs JP, Janssen PHM, Petersen AC, Kloprogge P, Risbev JS, Tuinstra W, Ravetz JR (2004) RIVM/MNP guidance for uncertainty assessment and communication: tool catalogue for uncertainty assessment. Tech. Rep. NWS-E-2004-37, Copernicus Institute and RIVM, Utrecht/Bilthoven, The Netherlands, ISBN 90-393-3797-7

Van der Sluijs JP, Craye M, Funtowicz S, Kloprogge P, Ravetz J, Risbey J (2005a) Combining quantitative and qualitative measures of uncertainty in model-based environmental assessment: the NUSAP system. Risk Anal 25(2):481-492. doi:10.1111/j.1539-6924.2005.00604.x

Van der Sluijs JP, Risbey JS, Ravetz J (2005b) Uncertainty assessment of VOC emissions from paint in the Netherlands using the NUSAP system. Environ Monit Assess 105(1-3):229-259. doi:10.1007/s10661-005-3697-7

Van Velzen EH, Jesse P, Cornelissen P, Coops H (2003) Stromingsweerstand vegetatie in uiterwaarden: deel 1 handboek versie-1 2003. RIZA report 2003.028, RIZA, The Netherlands (in Dutch)

Walker WE, Harremoës P, Rotmans J, Van der Sluijs JP, van Asselt MBA, Janssen PHM, Krayer von Kraus MP (2003) Defining uncertainty, a conceptual basis for uncertainty management in model-based decision support. Integr Assess 4(1):5-17

Wardekker JA, Van der Sluijs JP, Janssen PHM, Kloprogge P, Petersen AC (2008) Uncertainty communication in environmental assessments: views from the Dutch science-policy interface. Environ Sci Policy 11(7):627-641. doi:10.1016/j.envsci.2008.05.005

Warmink JJ, Janssen JAEB, Booij MJ, Krol MS (2010) Identification and classification of uncertainties in the application of environmental models. Environ Model Softw 25(12):1518-1527. doi:10.1016/j.envsoft.2010.04.011 